Document downloaded from:

http://hdl.handle.net/10251/64753

This paper must be cited as:

Robles Martínez, A.; Durán Pinzón, F.; Ruano García, MV.; Ribes Bertomeu, J.; Rosado Muñoz, A.; Seco Torrecillas, A.; Ferrer, J. (2015). Instrumentation, control, and automation for submerged anaerobic membrane bioreactors. Environmental Technology. 36(14):17951806. doi:10.1080/09593330.2015.1012180.

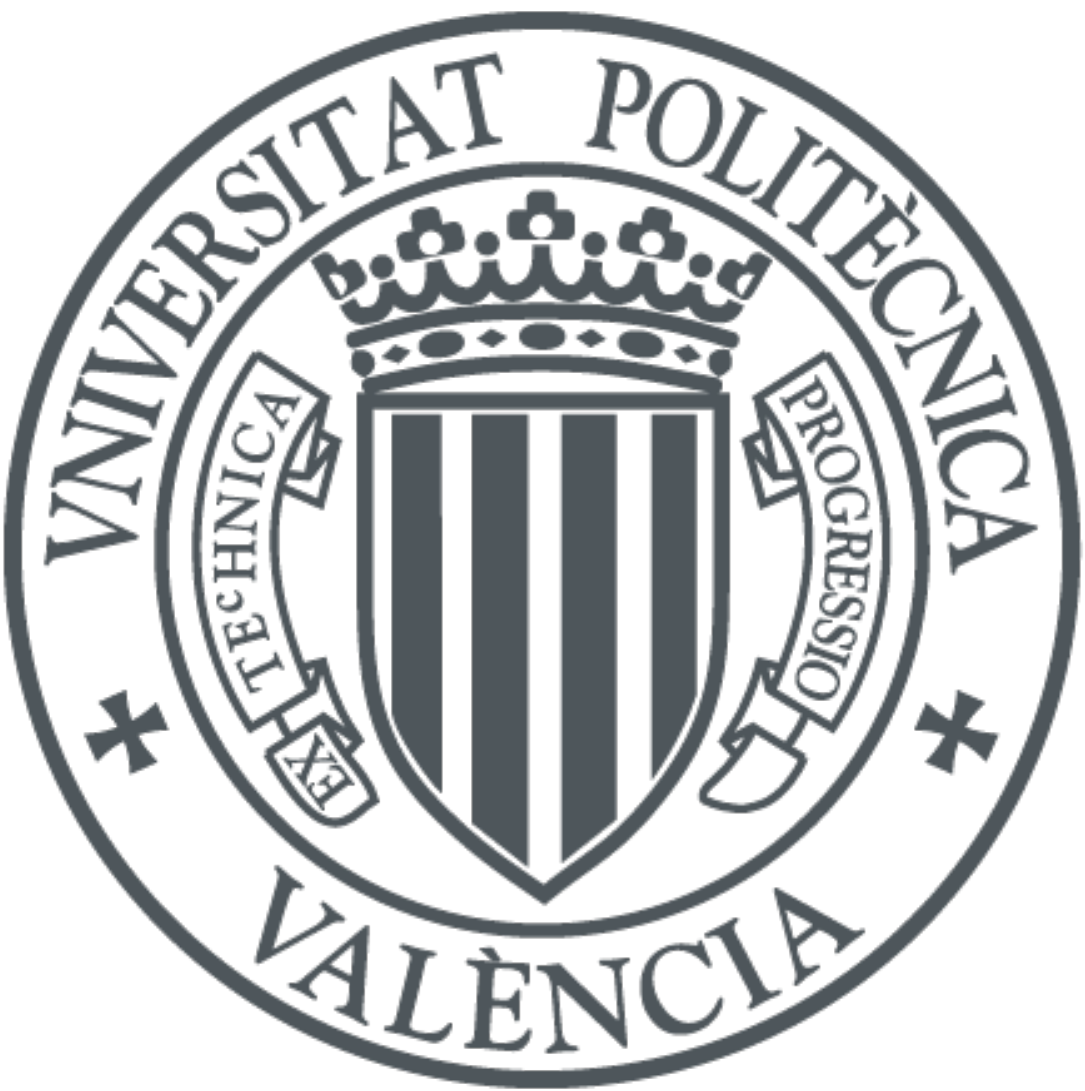

The final publication is available at

http://dx.doi.org/10.1080/09593330.2015.1012180

Copyright TAYLOR \& FRANCIS LTD

Additional Information 


\section{Instrumentation, control, and automation (ICA) for submerged anaerobic membrane bioreactors (AnMBR)}

Ángel Robles ${ }^{\mathrm{a}, *}$, Freddy Durán ${ }^{\mathrm{a}}$, María Victoria Ruano ${ }^{\mathrm{b}}$, Josep Ribes ${ }^{\mathrm{b}}$, Alfredo Rosado , Aurora Seco ${ }^{\mathrm{b}}$ and José Ferrer ${ }^{\mathrm{a}}$

${ }^{a}$ Institut Universitari d'Investigació d'Enginyeria de l'Aigua i Medi Ambient, IIAMA.

Universitat Politècnica de València. Camí de Vera, s/n. 46022. Valencia. Spain. (Email: ngerobma@upv.es; fredurpi@upv.es; jferrer@hma.upv.es)

${ }^{b}$ Departament d'Enginyeria Química. Escola Tècnica Superior d'Enginyeria.

Universitat de València. Avinguda de la Universitat, s/n. 46100. Burjassot. Valencia.

Spain. (Email:m.victoria.ruano@uv.es; josep.ribes@uv.es; aurora.seco@uv.es)

${ }^{c}$ Departament d'Enginyeria Electrónica. Escola Tècnica Superior d'Enginyeria.

Universitat de València. Avinguda de la Universitat, s/n. 46100. Burjassot. Valencia.

Spain. (Email: alfredo.rosado@uv.es)

* Corresponding author: Tel.: +34 9638799 61; Fax: +34 9638790 09. Email: ngerobma@upv.es

\section{Acknowledgements}

This research work was supported by the Spanish Ministry of Science and Innovation under grant CTM2008-06809-C02-01/02; and the Spanish Ministry of Economy and Competitiveness under grant CTM2011-28595-C02-01/02, jointly with the European Regional Development Fund (ERDF) and Generalitat Valenciana (GVA-ACOMP2013/203). 


\title{
Instrumentation, control, and automation (ICA) for submerged anaerobic membrane bioreactors (AnMBR)
}

\author{
A submerged anaerobic membrane bioreactor (AnMBR) demonstration plant \\ with two commercial hollow-fibre ultrafiltration systems (PURON ${ }^{\circledR}$, Koch \\ Membrane Systems, PUR-PSH31) was designed and operated for urban \\ wastewater treatment. An instrumentation, control, and automation (ICA) system \\ was designed and implemented for proper process performance. Several single- \\ input-single-output (SISO) feedback control loops based on conventional on-off \\ and PID algorithms were implemented to control the following operating \\ variables: flow-rates (influent, permeate, sludge recycling and wasting, and \\ recycled biogas through both reactor and membrane tanks), sludge wasting \\ volume, temperature, transmembrane pressure, and gas sparging. The proposed \\ ICA for AnMBRs for urban wastewater treatment enables the optimisation of this \\ new technology to be achieved with a high level of process robustness towards \\ disturbances.
}

Keywords: Demonstration plant; industrial-scale membranes; instrumentation, control and automation (ICA); urban wastewater treatment; submerged anaerobic membrane bioreactor (AnMBR).

\section{Introduction}

Submerged MBR is one of the most promising technologies in the wastewater treatment field [1]. The main benefits of using MBR technology instead of conventional activated sludge systems (CAS) for urban wastewater treatment are the following [2]: (1) obtaining solid- and microorganism-free effluent (high effluent quality); (2) reducing the footprint of the wastewater treatment plant (WWTP); (3) reducing the operating problems related to foaming; (4) decoupling hydraulic retention time (HRT) and sludge retention time (SRT) (i.e. high SRT can be achieved without increasing the reactor volume); and (5) intensifying the organic matter removal process due to a higher 
microbial biodiversity in the reactor (retention of the low-growth rate microorganisms). MBRs usually operate at high MLTS levels which contribute to membrane fouling: one of the main handicaps of membranes [2]. Membrane fouling reduces membrane permeability and increases operating and maintenance costs [3, 4].

Submerged anaerobic membrane bioreactors (AnMBRs) have emerged as a promising technology for urban wastewater treatment because not only do they feature the main advantages of MBRs, but they also offer the greater sustainability of anaerobic rather than aerobic processes: lower sludge production due to the low anaerobic biomass yield; lower energy consumption because no aeration is required; and the production of biogas that can be used as energy [5].

The treatment capacity of aerobic MBR for urban wastewater has significantly increased (maximum design flow-rates over 150,000 $\mathrm{m}^{3}$ day $^{-1}$ ) in recent years [6 - 8]. On the other hand, submerged AnMBR technology has been successfully applied for the treatment of industrial wastewater at full scale in the last years [9]. However, submerged MBR technology has not yet been applied to full-scale anaerobic urban wastewater treatment. Nevertheless, due to the above-mentioned advantages, the scientific community is showing increasing interest in the feasibility of full-scale implementation [10 - 14].

Several issues have been recognised elsewhere as potential drawbacks that must be solved before successfully implementing AnMBR technology for urban wastewater treatment, such as greater complexity than aerobic processes since many different microorganisms are involved with major syntrophic relationships between them; higher sensitivity to process overloads and other disturbances such as $\mathrm{pH}$ or organic acid 
inhibitions; and possible membrane fouling [2]. Therefore, an AnMBR system requires more sophisticated monitoring equipment, process control systems, and operating conditions than aerobic MBR systems, or other conventional anaerobic systems - such as up-flow anaerobic sludge blanket (UASB); expanded granular sludge blanket (EGSB); or anaerobic filters (AF). Therefore, due to the complexity of anaerobic processes in general, and of AnMBR systems in particular, the development of an instrumentation, control, and automation (ICA) system is required to successfully startup, stabilise, and optimise this new technology for urban wastewater treatment.

It is well-known that an ICA system is essential in WWTPs to facilitate system management and save manpower and energy [15 - 19]. ICA systems are needed to optimise the AnMBR performance in terms of energy consumption/production (i.e., operating cost vs. methanation) and COD degradation. The required control systems should take into account the main parameters of the process, such as SRT, HRT, transmembrane pressure (TMP), and recycled biogas flow-rate.

To investigate the possible full-scale implementation of AnMBR technology for treating urban wastewater, an AnMBR demonstration plant was designed and operated. An ICA system (built from industrially feasible equipment) was developed as part of the plant. The aim of this ICA system is to show the basis of the control structure required for adequate process performance. This ICA system will allow successfully implementing advanced controllers for optimised process performance. The AnMBR plant is being operated with real wastewater from the pre-treatment of the Carraixet WWTP (Valencia, Spain). Thus, the main disturbances that take place in full-scale plants are reproduced. The objective of this paper is to show how the developed ICA 
system has allowed us to enhance the overall process performance. This implementation will facilitate its subsequent full-scale application. The proposed ICA system provides valuable insights into the engineering problems and so it will help engineers to handle day-to-day tasks in full-scale plants of this type.

\section{Materials}

\subsection{Demonstration plant description and operation}

The AnMBR demonstration plant used in this study is fed with the effluent from the Carraixet WWTP pre-treatment (screening, degritter, and grease removal). The plant consists of an anaerobic reactor with a total volume of $1.3 \mathrm{~m}^{3}$ connected to two membrane tanks each with a total volume of $0.8 \mathrm{~m}^{3}$. Each membrane tank has one industrial-scale submerged hollow-fibre ultrafiltration membrane unit (PURON ${ }^{\circledR}$, Koch Membrane Systems, PUR-PSH31, with $0.05 \mu \mathrm{m}$ pores) with a total membrane surface of $30 \mathrm{~m}^{2}$. A rotofilter with a $0.5 \mathrm{~mm}$ screen size was installed as a pre-treatment system. One equalisation tank $\left(0.3 \mathrm{~m}^{3}\right)$ and one clean-in-place (CIP) tank $\left(0.2 \mathrm{~m}^{3}\right)$ are also included as main elements of the plant.

Figure 1a shows the flow diagram of the AnMBR demonstration plant. After further pre-treatment in the rotofilter (RF) and homogenisation in the equalisation tank (ET), the wastewater is pumped to the anaerobic reactor (AnR). To improve the stirring conditions of the anaerobic reactor and to favour stripping the produced gases from the liquid phase, a fraction of the produced biogas is recycled to this reactor. The sludge is continuously recycled through the external membrane tanks (MT) where the effluent is obtained by vacuum filtration. Another fraction of the produced biogas is also recycled 
to the membrane tanks from the bottom of each fibre bundle to minimise cake layer formation. With the aim of recovering the biogas bubbles extracted with the membrane effluent, a degasification vessel (DV) was installed between the MT and the vacuum pump. This DV consists of a widening pipe-section that is conic-shaped and so favours the accumulation of biogas at the top of this element. The obtained permeate is stored in the clean-in-place (CIP) tank. By using two membrane tanks in parallel, the AnMBR demonstration plant has been designed and automated with a high level of operating flexibility that enables the plant to work with either one or two membrane tanks.

Different transmembrane fluxes can be tested without affecting the HRT of the plant. To control the SRT in the system, a fraction of the sludge is intermittently extracted from the anaerobic reactor throughout the day.

The membrane operation was automated to enable the study of various relaxation and back-flush frequencies and durations. Membranes are normally operated according to a specific schedule involving a combination of different individual stages taken from a basic filtration-relaxation (F-R) cycle (see Figure 1b). In addition to the classical membrane operating stages (filtration, relaxation, and back-flush) the two stages shown below were also considered in the membrane operation:

Degasification: a typical disadvantage of dead-end, hollow-fibre membranes is the accumulation of biogas at the top of the fibres which reduces the effective filtration area. The degasification stage consists of a period of high flow-rate filtration that is carried out to enhance the filtration process efficiency by removing the accumulated biogas. 
Ventilation: This stage is similar to back-flush and permeate is pumped to the membrane tank through the degasification vessel instead of through the membrane. The aim of the ventilation stage is to recover the accumulated biogas in the degasification vessel.

The membrane performance is then established by a correct selection of the membrane operating mode. Figure $1 \mathrm{~b}$ shows the possible membrane operating modes. For instance, the operating mode defined by $X=2 ; Y=10 ; Z=50$ implies that a back-flush is carried out every two F-R cycles; a ventilation is carried out every ten F-R cycles; and a degasification followed by a ventilation is carried out every fifty F-R cycles.

For further details about this AnMBR demonstration plant see Giménez et al. [20] and Robles et al. [21].

\section{Proposed ICA for AnMBR systems}

The main goal of the proposed ICA is not only to facilitate system management and save manpower and energy, but also to allow achieving suitable process performances in terms of methanation and COD degradation. To this aim, the proposed ICA has been developed taking into account the main parameters that affect the performance of an AnMBR system. These key parameters were determined by using the knowledge gained with the operation of the demonstration plant. The following operating variables are manipulated for controlling the biological process: treatment flow-rate (controlling the HRT), sludge wasting volume (controlling the SRT), temperature, and gas sparging intensity in the anaerobic reactor. The main variables controlled for the physical separation process are: permeate flow-rate, TMP, sludge flow-rate recycled through the 
membrane tanks, and gas sparging intensity in the membrane tanks.

\subsection{Demonstration plant instrumentation}

On-line sensors and automatic devices were installed to automate and control the plant operation and provide on-line information about the state of the process. The main characteristics of the installed equipment are as follows: on-line availability of the provided signals; industrial readiness; generally low-cost (with the only exception of the gas composition analyser); resistance to corrosion; long lifespan; low and easy maintenance; and ATEX (explosive atmospheres) protection, which is essential in closed-air reactors containing biogas. In addition, because of the possible presence of $\mathrm{H}_{2} \mathrm{~S}$, it is necessary to install non-corrosive materials.

Figure 2 shows the flow diagram of the AnMBR plant including the instrumentation. The group of on-line sensors includes $\mathrm{pH}$-temperature transmitters (pH-T), oxidation-reduction potential (ORP), solids concentration transmitters (SIT), liquid-flow-rate transmitters (FIT), gas-flow-rate transmitters (GFIT), biogas composition analyser, biogas meter, level transmitters (LIT), and pressure transmitters (PIT). The group of actuators consists of the following: eight frequency converters that control the rotating speed of six pumps (P-1, P-2, P-12, P-22, P-11 and P-21) and two blowers (B-1 and B-2); one regulatory valve to control the biogas discharge according to the pressure in the system (V-2); two on-off control valves enabling the continuous recycling of the obtained permeate in the system ( $\mathrm{V}-14$ and $\mathrm{V}-24)$; and six on-off control valves aimed to control the sludge wastage, the heating/cooling water and the different membrane operating stages (V-1, V-3, V-12, V-13, V-22 and V-23). 


\subsection{Demonstration plant automation}

Due to the complexity of anaerobic processes in general, and AnMBR systems in particular, a complete network system is required to ensure a high level of system robustness towards disturbances. Therefore, a network system based on a high number of sensors-transmitters and actuators, a complete PLC, and an exhaustively designed SCADA was developed. This system enables a high level of process autonomy to be achieved thus minimising human supervision.

\subsection{Demonstration plant control}

The instrumentation installed is connected to a network system that includes several transmitters, a programmable logic controller (PLC), a PC to perform multi-parameter control, and data acquisition link connected to the PLC using an MPI-Profibus PCI internal card. Data logging and the plant control are carried out using a SCADA system installed in the PC (which centralises all the signals from the different sensors and actuators installed in the plant). In addition, the SCADA is linked to an OPC (OLE for process control) system that connects dedicated control applications to the SCADA of the plant. The plant control includes several lower layer control loops and an upper layer controller. The lower layer controllers consist of several classical PID and on-off controllers that are programmed to control the main operating variables. The upper layer controllers consist of advanced supervisory controllers such as, for instance, modelbased and fuzzy-logic-based control systems, which are programmed as dedicated control applications and are connected to the SCADA of the plant by the OPC protocol. The implementation of upper layer controllers enables the set-points of the main operating variables to be automatically established according to information gathered from the plant. 


\subsubsection{Lower layer controllers}

Figure 3 shows a simplified lay-out of the AnMBR demonstration plant including the lower layer controllers and their associated instrumentation. The lower layer control group consist of classical PID and on-off controllers designed to control the following operating variables: flow-rates (influent, permeate, sludge recycling and wasting, and recycled biogas through both reactor and membrane tanks); biogas pressure in the system; blower output pressure; transmembrane pressure; reactor temperature; and mixed liquor level. Table 1 summarises the lower layer controllers implemented in the AnMBR demonstration plant.

\subsubsection{Upper layer controllers}

Various upper layer controllers are generally needed to optimise system performance in terms of organic matter degradation, biogas production, or energy savings related, for instance, to filtration. The following indexes can be used to evaluate the performance of a AnMBR system: COD removal efficiency; methane yield $\left(\mathrm{Y}_{\mathrm{CH} 4}\right)$, which is defined as the amount of produced methane per unit of removed organic matter; and overall energy balance, which accounted for the energy consumption related to the wastewater treatment (heat and power) and the potential energy recovery from biogas.

So far, one dedicated application has been developed to control the organic loading rate (OLR) in this AnMBR system, which is described in the following section. 
3.3.2.1 Organic loading rate control. OLR is a key operation parameter affecting the anaerobic process performance. The OLR controller enables the organic matter entering the system to be controlled and it is aimed to improve the biological process performance in terms of COD removal efficiency and $\mathrm{Y}_{\mathrm{CH} 4}$. In addition, this controller can be applied when a regulatory tank is available and there is storage capacity for minimising variations derived from influent dynamics.

This upper layer controller consists of a fuzzy-logic-based control system that includes a single-input single-output (SISO) control structure. In this SISO control structure the control parameter is the OLR entering the system and the manipulated variable is the ratio between the duration of the filtration and the relaxation stage (manipulating the net permeate volume).

Fuzzy-logic theory was selected in this specific controller because of the following advantages offered by fuzzy control: (1) no detailed mathematical model is required; (2) human experience can be easily incorporated; (3) allows easy disturbance rejection; (4) can adapt to process changes; (5) only with a limited number of rules it can control very complex systems; (6) presents tolerance with the imprecision; and (7) presents capacity for modelling non-linear problems. In this respect, applying fuzzylogic calculations enables designing nonlinear controllers, without a detailed knowledge of the operating point nonlinearity, as would be required for a classical control design. Control systems of this type can be easily developed and tuned by using the expert knowledge of the plant operator. 
The OLR is calculated by means of the COD concentration entering the system and the measured net permeate flow-rate. The COD concentration is on-line estimated with Eq.1, since it was possible to correlate both influent total suspended solids (TSS, on-line monitored) and COD values (experimentally determined), which enables a reduction in the analytical monitoring requirements. Specifically, the experimentally determined influent COD concentration (determined according to method $2540 \mathrm{E}$ in [22]) showed a linear correlation with the on-line monitored influent TSS (measured by the influent TSS sensor, SIT-0) with a correlation coefficient $\left(\mathrm{R}^{2}\right)$ of 0.988 (see Eq. 1).

$$
C O D_{\text {ESTIMATED }}=1.342 \cdot T S S+151.2 \quad\left(R^{2}=0.988\right)
$$

Because the influent is sulphate rich (around $100 \mathrm{mg} \mathrm{S} \mathrm{L}^{-1}$ ), the OLR considered was related to the available COD for Methanogenic Archaea (MA) growth: OLR $\mathrm{MA}_{\text {. }}$ The influent sulphate is reduced to sulphide by sulphate-reducing bacteria (SRB) using organic matter as a carbon source. Since this concentration remained more or less constant throughout the experimental period, $\mathrm{OLR}_{\mathrm{MA}}$ is calculated using the available COD for MA to grow: $\mathrm{COD}_{\mathrm{MA}}$. $\mathrm{COD}_{\mathrm{MA}}$ is calculated with the influent $\mathrm{COD}$ concentration (estimated by Eq. 1); while the off-line sulphate influent concentration measurement in terms of $\mathrm{COD}\left(0.67 \cdot \mathrm{SO}_{4}^{3-}\right.$ in Eq. 2$)$ is calculated using the stoichiometric ratio, 0.67 , which represents the $\mathrm{kg}$ of sulphate reduced to sulphide per $\mathrm{kg}$ of COD degraded.

$$
C O D_{M A}=C O D-0.67 \cdot S O_{4}^{3-}
$$


The inputs to this fuzzy-logic-based control system are obtained by means of the OLR $_{\mathrm{MA}}$, which correspond to the error (Eq. 3) and the error difference (Eq. 4).

$$
e O L R_{M A}(k)=O L R_{M A}(k)-O L R_{M A_{S P}}
$$

Where:

- $e O L R_{M A}(k)$ : error of the $\mathrm{OLR}_{\mathrm{MA}}$ at the sample time

- $O L R_{M A}(k)$ : measured $\operatorname{OLR}_{\mathrm{MA}}$ at the sample time

- $O L R_{M A_{S P}}: \mathrm{OLR}_{\mathrm{MA}}$ set-point

$$
\Delta e O L R_{M A}(k)=e O L R_{M A}(k)-\delta \cdot e O L R_{M A}(k-R T)
$$

Where:

- $\Delta e O L R_{M A}(k)$ : error difference of the $\mathrm{OLR}_{\mathrm{MA}}$ at the sample time

- $\delta$ : modifying algebraic factor (Eq. 5)

- $e O L R_{M A}(k-R T)$ : error of the $\mathrm{OLR}_{\mathrm{MA}}$ at the previous sample time

- $\quad R T$ is the response time of the controller, i.e. the time interval between two control actions 
The $\mathrm{OLR}_{\mathrm{MA}}$ error difference variable will be negative or positive if the $\mathrm{OLR}_{\mathrm{MA}}$ tends to the set-point value or not. This $\mathrm{OLR}_{\mathrm{MA}}$ error difference variable includes a modifying algebraic factor that is defined in Eq. 5.

$$
\delta=\frac{e O L R_{M A}(k) \cdot e O L R_{M A}(k-R T)}{\left|e O L R_{M A}(k) \cdot e O L R_{M A}(k-R T)\right|}
$$

This factor has a negative sign when both $e O L R_{M A}(k)$ and $e O L R_{M A}(k-R T)$ have opposite signs. The error difference will be positive when both errors have opposite signs, taking into account that the OLR $\mathrm{R}_{\mathrm{MA}}$ tendency is moving away from the set-point value.

The fuzzy-logic-based controller determines the variation in the set point of the F/R ratio (i.e. $\Delta F / R_{S P}$ ) on the basis of two inputs obtained from the organic loading rate, i.e. error (Eq. 3) and error difference (Eq. 4). The structure of this controller is, therefore, a fuzzy equivalent of the classical PD controller. The output control action is defined by Eq. 6:

$$
F / R_{S P}(k)=F / R_{S P}(k-R T)+\Delta F / R_{S P}(k)
$$

Where:

- $F / R_{S P}(k): F / R$ set-point at the control time

- $F / R_{S P}(k-R T)$ : methane flow-rate set-point at the previous control time 
- $\Delta F / R_{S P}(k)$ : modification in the $\mathrm{F} / \mathrm{R}$ ratio set-point at the control time

With regard to the fuzzification stage, three Gaussian membership functions are considered for the $e O L R$ and the $\triangle e O L R$ : negative $(N)$, zero $(Z)$, and positive $(P)$. For the defuzzification stage, four singleton functions were defined as output linguistic variables: high negative $(H N)$, low negative $(L N)$, low positive $(L P)$, and high positive $(H P)$. Table 2 shows the inference rules defined for the proposed fuzzy-logic-based control system. As Table 2 shows, each inference rule consists of an if-then fuzzy implication that is built by the fuzzy intersection (AND) of two input fuzzy sets (N, Z, P) from the input variables $\left(e O L R_{M A}\right.$ and $\left.\triangle e O L R_{M A}\right)$. The selection of the inference rule subset was carried out on the basis of the know-how of the process.

The output linguistic variables were obtained using the Larsen’s fuzzy inference method [23], which includes the Max-Prod operator. The defuzzification stage was carried out using the height defuzzifier method [24].

To avoid possible operational problems, i.e. overloads and/or washouts of soluble compounds, the net permeate flow-rate was only modified in a pre-defined HRT range bounded by the following constraint (Eq. 7):

$$
H R T_{\min } \leq H R T \leq H R T_{\max }
$$

Where: 
- $H R T_{\min }$ : 10 hours, minimum HRT (corresponding to a maximum permeate flowrate of $5000 \mathrm{~L} \mathrm{~d}^{-1}$ ).

- $H R T_{\text {max }}: 24$ hours, maximum HRT (corresponding to a minimum permeate flowrate of $\left.2000 \mathrm{~L} \mathrm{~d}^{-1}\right)$.

\section{Results and discussion}

\subsection{Lower layer control performance}

Once the basic lower layer control performance was assessed at the demonstration plant, two critical issues were detected. One key point was the initial overshoot derived from the initiation of given PID controllers (tuned by classical methods, e.g. Ziegler-Nichols) that have a frequency converter as final control element (e.g. flow-rate control in permeate pumps). The other issue detected is associated with the closed-configuration of this wastewater treatment process, where the mixed liquor volume should be maintained constant to avoid possible process disturbances related to head-space pressure variations.

\subsubsection{Starting-up correcting action for the PID controllers}

As mentioned before, one critical issue detected in the performance of the plant was the initial overshoot derived from the initiation of the PID controllers related to flow-rate control in permeate pumps. Specifically, permeate pumps are frequently turned-on and turned-off at all time due to the change between the different stages that define the membrane operating mode (see, for instance, [20]). Thus, a flow overshoot (see PID performance in Figure 4) derived from each membrane operating stage initiation was 
observed. This overshoot critically affects the filtration process performance.

To avoid this initial overshoot, a starting-up correcting action was programmed. This correcting action was applied to the above-mentioned controllers whose final control element is a frequency converter that modifies the rotating speed of equipment that is continuously turned-on and turned-off at all time (i.e. permeate pumps). The proposed correcting action (defined in this study as FF operating mode) consists of operating at an initial time ( $t_{1}$ in Eq. 8 and Figure 4, which was set to 10 seconds in accordance with the ramp-up time set for the frequency converter) at fixed frequency converter output before starting the PID controller. This fixed frequency converter output value is calculated as the average operating frequency converter output during a given time interval ( $t_{2}$ in Eq. 8 and Figure 4 , set to one quarter of the total operating stage duration) in the previous homologous membrane operating stage (see Eq. 8). For instance, the duration of a given filtration stage was set to 60 seconds in this study (see Figure 4). Therefore, the initial fixed frequency converter output to be applied in the following filtration stage was calculated as the average operating frequency converter output resulting from the last $t_{2}$ seconds (i.e. $\left.t_{2}=60 / 4\right)$ of the running filtration stage $\left(t_{2}\right.$ in Eq. 8 and Figure 4). The selected value for $t_{2}$ was enough for capturing proper initial conditions for the upcoming homologous membrane operating stage since: 1) properly controlled flow-rate is considered to be achieved at the end of each membrane operating stage (see Figure 4), and 2) no considerable changes in the flow-rate set-point are expected between successive homologous membrane operating stages. Figure 4 shows an example of the results obtained using both the single PID controller and FF+PID control combination. Figure 4a shows how the operating frequency converter output of the pump is initially established (for 10 seconds) in a value close to the expected 
operating value (around $17 \mathrm{~Hz}$, calculated from the monitored operating frequency converter output in the previous filtration stage). As a result of operating in FF+PID control mode, a start-up of the PID controller from an initial situation far from the established flow-rate set-point is avoided, which results in a high level of stability around the established flow-rate set-point $\left(400 \mathrm{~L} \mathrm{~h}^{-1}\right)$ in a short period of time.

$$
\left.\overline{v_{i}}\right|_{k_{0}} ^{k=k_{0}+t_{1}}=\frac{\sum_{k=k_{f}-t_{2}}^{k_{f}} v_{i-1}(k)}{n}
$$

Where:

- ${\overline{v_{i}}}_{k_{0}}^{k=k_{0}+t_{1}}$ is the frequency converter output fixed during a given time interval $\left(t_{1}\right)$ in the $i^{\text {th }}$ membrane operating stage before starting the PID controller.

- $t_{1}$ is the initial time interval within the pump is operated at fixed frequency converter output. $t_{1}$ was set to 10 seconds in this study.

- $k_{0}$ is the initiation time of the $i^{\text {th }}$ membrane operating stage.

- $\frac{\sum_{k=k_{f}-t_{2}}^{k_{f}} v_{i-1}(k)}{n}$ : is the average frequency converter output during a given time interval $\left(t_{2}\right)$ in the $(i-1)^{t h}$ homologous membrane operating stage.

- $t_{2}$ is the time interval within the fixed frequency converter output is calculated. $t_{2}$ was set to one quarter of the total operating stage duration in this study.

- $\quad k_{f}$ is the stop time of the $(i-1)^{t h}$ homologous membrane operating stage. 
- $v_{i-1}(k)$ is the discrete measurement of the frequency converter output at time $k$ during the time interval $t_{2}$.

- $n$ is the number of discrete measurements of the frequency converter output recorded during the time interval $t_{2}$.

The performance of the proposed correcting action was assessed by determining the integral of absolute error (IAE). IAE resulted in 0.73 and 0.43 when operating in PID and FF+PID control mode, respectively. It corresponds to an IAE reduction of 43.5\%. Hence, operating in FF+PID control mode may be required to maintain filtration process working correctly.

\subsubsection{Mixed liquor level control}

As an example, Figure 5 shows the AnMBR performance operated at: (1) a constant mixed liquor volume; and (2) variable mixed liquor volume. In particular, Figure 5a depicts the mixed liquor level in the anaerobic reactor and the feed pump frequency. Until hour 2.5, the AnMBR plant operated at a constant mixed liquor level. In this case, this constant level set-point in the anaerobic reactor was maintained by a PID controller that governed the performance of the permeate pump. In this respect, the PID controller established indirectly a transmembrane flux proportional to the influent flow-rate entering the system. From 2.5 to 6 hours in Figure 5, the plant was operated with an effluent flow-rate lower than the influent flow-rate, which resulted in a variable mixed liquor level. In this case, the feed pump was operated intermittently between two security level threshold values. In particular, the influent pump is stopped when a maximum mixed liquor level is reached and it is started when the mixed liquor level 
achieves the established 'on' level value. Important to highlight is that variations in the mixed liquor level affects the MLTS concentration (affecting the physical separation process performance), as well as other operating variables such as head-space pressure, blower output pressure, and blower operating frequency.

Figure 5b illustrates the effect of a variable mixed liquor level on the abovementioned variables: AnMBR head-space pressure; blower output pressure; and blower operating frequency. As Figure 5b shows, any variation in the mixed liquor level results in an inversely proportional variation of the blower output pressures, as well as in a proportional variation in the head-space pressure and blower operating frequencies. As regards AnMBR head-space pressure, an increase and decrease in the mixed liquor level results in an increase and decrease in the AnMBR head-space pressure, respectively. This behaviour is caused by the corresponding compression and expansion of the biogas in the AnMBR head-space. These level oscillations cause two effects on blower output pressure: (1) an increase in the level results in an increase in the water column resistance to be overcome by the gas flow entering the corresponding tank; and (2) reductions in the AnMBR head-space increases the AnMBR head-pressure, and so increase the total resistance in the output zone of the blowers. Therefore, high energy consumption is required to maintain fixed biogas flow-rates. On the other hand, a decrease in the mixed liquor level can result in an excessive biogas recirculation to the corresponding tank when operating in fixed pressure control mode. Excessive biogas flow-rates can result in various operating problems such as foaming. Low biogas flowrates can also result in other operating problems: insufficient gas sparging intensities for membrane scouring, weak mixing intensities in the AnMBR system, death zones in the anaerobic reactor, and so on. 
IAE resulted in 0.93 and 10.25 when running with and without mixed liquor level control, respectively. It corresponds to an IAE reduction of 90.5\%. Therefore, a proper control strategy to maintain constant mixed liquor level such as the one shown in Figure 5 (until hour 2.5 in the figure) is essential to maintain the AnMBR system working correctly.

\subsection{OLR controller performance}

Figure 6 shows the results of the performance of the OLR controller. The set-point for the $\mathrm{OLR}_{\mathrm{MA}}$ in this experimental period was set to $1.4 \mathrm{~kg} \mathrm{COD} \mathrm{d}^{-1}$. Figure 6 a shows the evolution of the resulting $\mathrm{OLR}_{\mathrm{MA}}$, as well as the $\mathrm{F} / \mathrm{R}$ ratio regulated by the control system. Figure $6 \mathrm{~b}$ shows the evolution of the COD and $\mathrm{COD}_{\mathrm{MA}}$, and the resulting permeate flow-rate. As Figure 6 illustrates, the controller maintained the controlled variable at values close to the established set-point when operating in the established HRT range. Figure $6 \mathrm{~b}$ shows that the effluent permeate flow-rate reached its maximum established value during hours 17-19, 32-42, 50-68, and 72-76 (corresponding to 10 hours of HRT at minimum fixed value). In these periods the controller could not increase the influent flow-rate and so the $\mathrm{OLR}_{\mathrm{MA}}$ decreased (see Figure 6a). Moreover, when the HRT remained in the established operating range the controller maintained the $\mathrm{OLR}_{\mathrm{MA}}$ close to its set-point even when working with high total COD influent oscillations (from 350 to $750 \mathrm{mg} \mathrm{COD} \mathrm{L}^{-1}$ ).

Results from Figure 6 show a satisfactory performance of the fuzzy-logic-based controller proposed in this work as the $\mathrm{OLR}_{\mathrm{MA}}$ resulted in a deviation below $10 \%$ of the established set-point (1.4 kg COD d ${ }^{-1}$ ) when no interaction of the threshold HRT values 
was reached. It is important to highlight that this control system was operated under similar conditions to those found in full-scale plants, and that is easy to operate and adaptable to new operational requirements.

The proposed ICA makes plant operating very flexible with suitable and stable biological and physical separation process performances. The know-how acquired after almost three years of plant operation experience has contributed to develop and enhance this ICA for AnMBR technology. The proposed ICA offers high process stability, which is essential to control the key operating issues of AnMBR technology. Indeed, a successful implementation of an adequate ICA system for AnMBR technology is essential for optimising process performance; and the proposed ICA system is a promising alternative for AnMBR systems operation.

\subsection{Chances for full-scale implementation}

As previously commented, one key step for adequately implement submerged AnMBR technology for urban wastewater treatment on an industrial scale is to develop an appropriate ICA system. In this respect, the ICA system proposed in this study facilitates the system management and allows improving AnMBR technology, thus saving manpower and energy. The developed control structure entails several lower layer controllers and an upper layer controller which enables the overall controllability of AnMBR technology. The developed control algorithms offer high process stability towards disturbances and allow improving membrane performance on an industrial scale. The high level of flexibility provided by the developed control structure enables various upper layer controllers to be implemented to further optimise the performance of the AnMBR system. 
The suggested ICA system was developed taking advantage of the industrially feasible on-line sensors now available for monitoring key operating variables at full scale (i.e. pressure, flows, total solids, levels, etc.). Moreover, it was implemented in a submerged AnMBR demonstration plant (i.e. high-capacity reactor) fitted with industrial-scale membrane units. In addition, the AnMBR was fed with real urban wastewater at ambient conditions, thus most of the main disturbances that take place in full-scale plants were reproduced, such as variations in the influent flow and load, variations in the environment conditions (e.g. temperature), etc.

Hence, the proposed ICA system, can be directly extrapolated to the full scale since it was tested in real conditions and using both full-scale membrane units and highcapacity reactors.

\section{Conclusions}

An ICA system for AnMBR systems is presented in this paper. It has been implemented and tested in an AnMBR demonstration plant. Several lower layer control loops have been implemented and are described. These control algorithms enable a suitable and stable process performance. Moreover, various modifications to the classical PID controllers were implemented to enhance global process performance. The level of automatic control of the proposed ICA system reduces the involvement of operators and laboratory personnel, lowers operational costs, and improves process stability following input disturbances. 


\section{References}

[1] Ben ARM, Semmens MJ. Membrane bioreactors for wastewater treatment and reuse: a success story, Water Sci. Technol. 2002, 47: 1-5.

[2] Judd SJ, Judd C. Principles and Applications of Membrane Bioreactors in Water and Wastewater Treatment. Second Edition, Elsevier, London, UK; 2011.

[3] Chang IS, Clech PL, Jefferson B, Judd S. Membrane fouling in membrane bioreactors for wastewater treatment, J. Environ. Eng. 2002, 128: 1018-1029. [4] Tran TM, Stuetz RM, Chen V, Le-Clech P. Advanced characterization of fouling in membrane coupled with upflow anaerobic sludge blanket process. Environ. Technol. 2013, 34: 2799-2807.

[5] Raskin L. Anaerobic Membrane Bioreactors for Sustainable Wastewater Treatment. WERF Report U4R08; 2012.

[6] Kraemer JT, Menniti AL, Erdal ZK, Constantine TA, Johnson BR, Daigger GT, Crawford GV. A practitioner's perspective on the application and research needs of membrane bioreactors for municipal wastewater treatment. Bioresource Technol. 2012, 122: $2-10$.

[7] Singhania RR, Christophe G, Perchet G, Troquet J, Larroche C. Immersed membrane bioreactors: An overview with special emphasis on anaerobic bioprocesses. Bioresource Technol. 2012, 122: 171 - 180.

[8] Raffin M, Germain E, Judd S. Wastewater polishing using membrane technology: a review of existing installations. Environ. Technol. 2013, 34: 617-627.

[9] Dereli RK, Ersahin ME, Ozgun H, Ozturk I, Jeison D, van der Zee F, van Lier JB. Potentials of anaerobic membrane bioreactors to overcome treatment limitations induced by industrial wastewaters. Bioresource Technol. 2012, 122: 160 - 170. 
[10] Skouteris G, Hermosilla D, López P, Negro C, Blanco A. Anaerobic membrane bioreactors for wastewater treatment: A review. Chem. Eng. J. 2012, 198/199: 138 148.

[11] Smith AL, Stadler LB, Love NG, Skerlos SJ, Raskin L. Perspectives on anaerobic membrane bioreactor treatment of domestic wastewater: A critical review. Bioresource Technol. 2012, 122: 149 - 159.

[12] Stuckey DC. Recent developments in anaerobic membrane reactors. Bioresource Technol. 2012, 122: 137 - 148.

[13] Lin H, Peng W, Zhang M, Chen J, Huachang H, Zhang Y. A review on anaerobic membrane bioreactors: Applications, membrane fouling and future perspectives. Desalination. 2013, 314: 169 - 188.

[14] Ozgun H, Dereli RK, Ersahin ME, Kinaci C, Spanjers H, van Lier JB. A review of anaerobic membrane bioreactors for municipal wastewater treatment: Integration options, limitations and expectations. Sep. Purif. Technol. 2013, 118: 89 - 104. [15] Jeppsson U, Alex J, Pons MN, Spanjers H, Vanrolleghem PA. Status and future trends of ICA in wastewater treatment - a European perspective. Water Sci. Technol. 2002, 45: $485-494$.

[16] Vanrolleghem PA, Lee DS. On-line monitoring equipment for wastewater treatment processes: state of the art. Water Sci. Technol. 2003, 47: 1 - 34.

[17] Olsson G, Nielsen MK, Yuan Z, Lynggaard-Jensen A, Steyer JP. Instrumentation, control and automation in wastewater systems. IWA Publishing; 2005. London, UK. [18] Haimi H, Mulas M, Sahlstedt K, Vahala R. Advanced operation and control methods of municipal wastewater treatment processes in Finland. Water and Wastewater Engineering, Helsinki University of Technology. Helsinki, Finland. I.S.B.N.: 978-951-22-9975-1; 2009. 
[19] Ruano MV, Ribes J, Seco A, Ferrer J. Low cost-sensors as a real alternative to online nitrogen analysers in continuous systems. Water Sci. Technol. 2009, 60: 3261 3268.

[20] Giménez JB, Robles A, Carretero L, Durán F, Ruano MV, Gatti MN, Ribes J, Ferrer J, Seco A. Experimental study of the anaerobic urban wastewater treatment in a submerged hollow-fibre membrane bioreactor at pilot scale. Bioresource Technol. 2011, 102: $8799-8806$.

[21] Robles A, Ruano MV, García-Usach F, Ferrer J. Sub-critical filtration conditions of commercial hollow-fibre membranes in a submerged anaerobic MBR (HF-SAnMBR) system: The effect of gas sparging intensity. Bioresource Technol. 2012, 114: 247 254.

[22] American Public Health Association/American Water Works Association/Water Environmental Federation, Standard methods for the Examination of Water and Wastewater, 21st edition, Washington DC, USA; 2005.

[23] Larsen PM. Industrial application of fuzzy logic control. Int. J. Man-Mach. Stud. 1980, 12, $3-10$.

[24] Mendel JM. Fuzzy logic systems for engineering: a tutorial. Proc. IEEE. 1995, 83: $345-375$. 